\title{
Clarity and clairvoyance: Review and prediction of management guidelines for early stage lung cancer
}

\author{
Bryan M. Burt, MD
}

\footnotetext{
From the Division of General Thoracic Surgery, Department of Surgery, Baylor College of Medicine, Houston, Tex

Disclosures: Author has nothing to disclose with regard to commercial support.

Received for publication Jan 17, 2017; accepted for publication Jan 28, 2017; available ahead of print March 6 , 2017.

Address for reprints: Bryan M. Burt, MD, Division of General Thoracic Surgery, Department of Surgery, Baylor College of Medicine, One Baylor Plaza, BCM 390, Houston, TX 77005 (E-mail: bryan.burt@bcm.edu).

J Thorac Cardiovasc Surg 2017;153:1563-4

$0022-5223 / \$ 36.00$

Copyright (C) 2017 by The American Association for Thoracic Surgery

http://dx.doi.org/10.1016/j.jtcvs.2017.01.040
}

The National Comprehensive Cancer Network (NCCN) clinical practice guidelines in oncology are a set of recommendations designed to support health care professionals in the diagnosis, treatment, and management of patients with cancer. In the United States, this document is referred to by physicians in academic, community, and private practices, and by residents and students caring for patients and preparing for board examinations. This document defines expectations of care for many patients with cancer and is the scripture routinely referred to in tumor boards around our country. It is a primary component of the "standard of care" in oncology.

Recommendations issued in the NCCN guidelines are established on the basis of available evidence and expert opinion, and it has been shown that adherence to these guidelines correlates favorably with survival outcomes ${ }^{1,2}$ Even though these guidelines are frequently updated, the accumulation of reproducible evidence necessary to amend them may take years to amass. In this issue of the Journal, Eguchi and Adusumilli ${ }^{3}$ present a clear and clairvoyant account of published work that identifies and stratifies patients with early stage lung cancer who are at high risk of recurrence or death, and they provide a glimpse of future management standards.

A central theme of this article is the influence of lung adenocarcinoma histologic subtype on patient care, including implications for invasive mediastinal staging, extent of resection, and adjuvant systemic therapy. For example, we have become increasingly aware that micropapillary and solid predominant histologic variants of lung adenocarcinoma are associated with increased of occult N2 disease, ${ }^{4}$ suggesting that patients with these histologic types may benefit from preoperative invasive mediastinal staging. Currently, NCCN guidelines ${ }^{5}$ recommend invasive mediastinal staging for clinical stage IB-IIIA non-small cell lung cancer, and "consideration" of invasive mediastinal staging for clinical stage IA disease. However, a recent multi-institutional prospective trial has called this practice into question. ${ }^{6}$ Among 90 patients

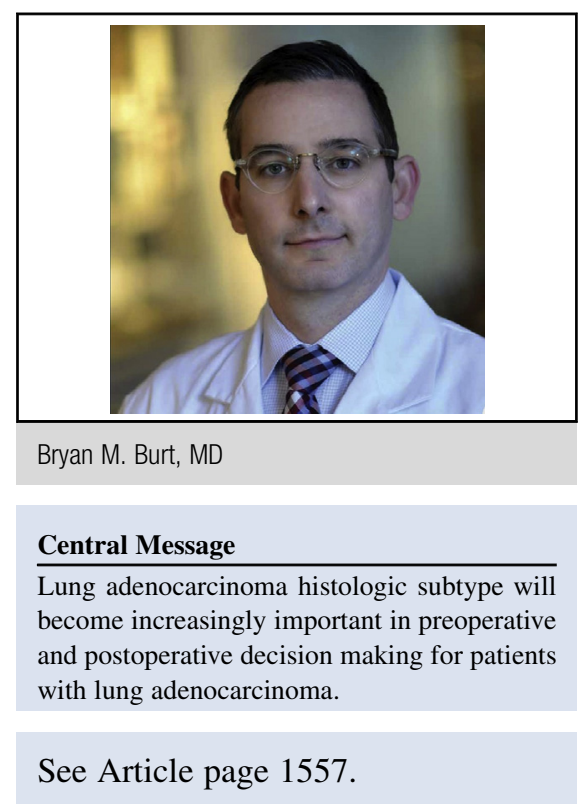

with clinical stage I NSCLC who were considered at risk for occult N2 disease (T2N0 or T1N0 with standardized uptake value $>10$ by positron emission tomography), mediastinoscopy detected occult N2 disease in only $1.1 \%$ of patients. Mean tumor size was substantial at $4.3 \mathrm{~cm}$, ranging from 1.3 to $12 \mathrm{~cm}$. Taken together, we may expect to see a refinement of national guidelines in upcoming years regarding recommendations for invasive mediastinal staging that may very well incorporate tumor histologic subtype.

In their review, Eguchi and Adusumilli ${ }^{3}$ highlight recent evidence supporting an elevated risk of recurrence for patients undergoing sublobar resection of adenocarcinoma tumors with micropapillary and solid predominant histology compared with lobectomy. ${ }^{7}$ In contrast, sublobar resection is associated with excellent long-term survival outcomes for preinvasive adenocarcinoma in situ and minimally invasive adenocarcinoma lesions, which are well represented radiographically as predominantly ground glass nodules. ${ }^{8,9}$ Currently, the NCCN guidelines have begun to consider such elements in their recommendation of sublobar resection as an alternative treatment for patients with peripheral nodules no larger than $2 \mathrm{~cm}$ with pure adenocarcinoma in situ pattern or at least $50 \%$ ground glass appearance. ${ }^{5}$ As our collective experience of preoperative determination of lung adenocarcinoma histologic subtype improves, whether through core needle biopsy or 
radiographic-pathologic correlation, we may anticipate that preoperative adenocarcinoma histologic subtype will play an increasing role in the decision making underlying the choice of lobar versus sublobar resection.

Finally, Eguchi and Adusumilli ${ }^{3}$ undertake a timely discussion of a variety of postresection pathologic variables that are associated with prognosis, highlighting the increased recurrence after resection of any adenocarcinoma tumor that contains some degree of high-grade histologic type, such as micropapillary or solid predominant. ${ }^{7,10}$ Currently, the NCCN recommends consideration of adjuvant chemotherapy for patients with pathologic stage $1 \mathrm{~b}$ (T2aN0) and node-negative stage II cancers in the presence of certain high-risk features, including vascular invasion, wedge resection, size greater than $4 \mathrm{~cm}$, and visceral pleural involvement. In addition to important roles in preoperative decision making, we can anticipate that adenocarcinoma histologic subtype may become a high-risk feature that will influence recommendations for adjuvant systemic therapy.

\section{References}

1. Worhunsky DJ, Ma Y, Zak Y, Poultsides GA, Norton JA, Rhoads KF, et al. Compliance with gastric cancer guidelines is associated with improved outcomes. J Natl Compr Canc Netw. 2015;13:319-25.
2. Hines RB, Barrett A, Twumasi-Ankrah P, Broccoli D, Engelman KK, Baranda J, et al. Predictors of guideline treatment nonadherence and the impact on survival in patients with colorectal cancer. J Natl Compr Cancer Netw. 2015; 13:51-60.

3. Eguchi T, Adusumilli PS. Risk stratification for lung nodules: size isn't everything. J Thorac Cardiovasc Surg. 2017;153:1557-62.

4. Yeh YC, Kadota K, Nitadori J, Sima CS, Rizk NP, Jones DR, et al. International Association for the Study of Lung Cancer/American Thoracic Society/European Respiratory Society classification predicts occult lymph node metastasis in clinically mediastinal node-negative lung adenocarcinoma. Eur J Cardiothorac Surg. 2016;49:e9-15.

5. Ettinger DS, Wood DE, Akerley W, Bazhenova LA, Borghaei H, Camidge DR, et al. National Comprehensive Cancer Network. Non-small cell lung cancer, version 6.2015. J Natl Compr Canc Netw. 2015;13:515-24.

6. Fernandez FG, Kozower BD, Crabtree TD, Force SD, Lau C, Pickens A, et al. Utility of mediastinoscopy in clinical stage I lung cancers at risk for occult mediastinal nodal metastases. J Thorac Cardiovasc Surg. 2015;149: 35-41. 42.e1.

7. Nitadori J, Bograd AJ, Kadota K, Sima CS, Rizk NP, Morales EA, et al. Impact of micropapillary histologic subtype in selecting limited resection vs lobectomy for lung adenocarcinoma of $2 \mathrm{~cm}$ or smaller. J Natl Cancer Inst. 2013;105: 1212-20.

8. Cho JH, Choi YS, Kim J, Kim HK, Zo JI, Shim YM. Long-term outcomes of wedge resection for pulmonary ground-glass opacity nodules. Ann Thorac Surg. 2015;99:218-22

9. Tsutani Y, Miyata Y, Nakayama H, Okumura S, Adachi S, Yoshimura M, et al. Appropriate sublobar resection choice for ground glass opacity-dominant clinical stage IA lung adenocarcinoma: wedge resection or segmentectomy. Chest. 2014; 145:66-71.

10. Cha MJ, Lee HY, Lee KS, Jeong JY, Han J, Shim YM, et al. Micropapillary and solid subtypes of invasive lung adenocarcinoma: clinical predictors of histopathology and outcome. J Thorac Cardiovasc Surg. 2014;147:921-8.e2. 